\title{
Biodegradação de resíduos lignocelulósicos gerados na bananicultura e sua valorização para a produção de biogás
}

\author{
0zair Souza ${ }^{1,2}$, Mauri Federizzi' ${ }^{2}$, Bruna Coelho ${ }^{1}$, Theodoro M. Wagner ${ }^{1} \&$ Elisabeth Wisbeck ${ }^{1,2}$
}

RESUMO

Propôs-se, neste trabal ho, avaliar a potencialidade do uso de resíduos lignocelulósicos da bananicultura como substrato de fermentação do processo de metanização. Os resíduos casca de banana, engaço, folhas e pseudocaule da bananeira Musa cavendischii, foram biodegradados a $30^{\circ} \mathrm{C}$ e pH 7,2, em diferentes volumes de trabalho, empregando-se como biodigestor frascos Erlenmeyer, garrafas plásticas e biorreator de bancada. A composição ideal do substrato para a metanização foi definida como: $50 \% \mathrm{~m} \mathrm{~m}^{-1}$ de cascas, $25 \%$ de folhas e $25 \%$ de pseudocaule. 0 engaço, por apresentar baixa velocidade de biodegradação em comparação com as demais biomassas, não foi recomendado para a metanização conjunta dos resíduos. A hidrólise ácida prévia do substrato foi prejudicial à produção de biogás visto que, além de conduzir à formação de $\mathrm{H}_{2} \mathrm{~S}$ no biogás gerado, inibiu a formação de $\mathrm{CH}_{4}$. $\mathrm{O}$ rendimento máximo em biogás, obtido em biodigestor de bancada empregando-se substrato in natura, foi de $244 \mathrm{~L}_{\text {CNTP }} \mathrm{kg}^{-1} \mathrm{ST}$ com $66,8 \% \mathrm{v} \mathrm{v}^{-1}$ de $\mathrm{CH}_{4}$.

Palavras-chave: metanização, biodigestão anaeróbia, gás metano

\section{Biodegradation of lignocellulosics residues generated in banana cultivation and its valorization for the production of biogas}

\begin{abstract}
This study aimed to evaluate the capability of using lignocellul osic residues from banana cultivation as a fermentation substrate of the methanization process. The following Musa cavendischii residues were evaluated: bananas peels, stalk, leaves and the pseudostem. The fermentation studies were developed at $30{ }^{\circ} \mathrm{C}$ and $\mathrm{pH} 7.2$ with different working volumes in Erlenmeyers flasks, plastic bottles and bioreactor bench. The ideal composition of the methanization substrate was set containing: $50 \%$ (w/w) of peels, $25 \%$ of leaves and $25 \%$ of pseudostem. The stalk, presenting a lower rate of biodegradation in comparison to other biomasses, was not recommended for the methanization together with such residues. The acid hydrolysis advance of the substrate was detrimental to the production of biogas. In addition to making possible the production of $\mathrm{H}_{2} \mathrm{~S}$ in biogas generated, it inhibited the formation of $\mathrm{CH}_{4}$. The maximum yield of biogas, obtained in biodigestor bench of employing substrate in nature, was $244 \mathrm{~L}_{\mathrm{CNTP}} \mathrm{kg}^{-1} \mathrm{ST}$ with $66.8 \%(\mathrm{v} / \mathrm{V})$ of $\mathrm{CH}_{4}$.
\end{abstract}

Key words: methanization, anaerobic digestion, methane gas

1 DEQ/UNIVILLE, CP 246, CEP 89201-972, Joinville, SC. Fone: (47) 3461-9056. E-mail: osouza@univille.br, bruna.coelho@ibest.com.br, theowag@terra.com.br ewisbeck@univille.br

2 Mestrado em Engenharia de Processos/U NIVILLE. Fone: (47) 3461-9180. E-mail: mauriengambi@hotmail.com 


\section{INTRODUÇãO}

A bananeira é uma das principais frutíferas em exploração no Brasil; entretanto, a quantidade de bananas produzidas anualmente no País só é superada pela de laranjas. A bananeira é cultivada, sem exceção, em todos os estados da Federação. Em 2005, o estado catarinense, segundo maior produtor nacional de bananas, produziu 668 mil toneladas da fruta, principalmente as das espécies Musa sapientum e Musa cavendischii, popularmente conhecidas na região como banana branca e banana nanica, respectivamente (CEPA, 2006).

Dados da EMBRAPA (2006) mostram que, de cada 100 $\mathrm{kg}$ de frutas colhidas em 2006, $46 \mathrm{~kg}$ não foram aproveitados. Além desse rejeito, a cultura da banana gera outros resíduos no campo provenientes da sua industrialização. De acordo com dados levantados em uma empresa de alimentos do município de Garuva, um dos maiores produtores de banana nanica na região nordeste do estado de Santa Catarina, para cada tonelada de banana industrializada aproximadamente 3 toneladas de pseudocaule, $160 \mathrm{~kg}$ de engaços, $480 \mathrm{~kg}$ de folhas e $440 \mathrm{~kg}$ de cascas são gerados.

O aproveitamento desses resíduos na produção de biogás, não só possibilitaria a redução da poluição ambiental mas permitira agregar valor à cultura da banana, que tem enfrentado, nos últimos anos, grandes desafios gerados pela oscilação do seu preço no mercado nacional.

A composição do biogás, combustível resultante da biodegradação anaeróbia de matérias orgânicas, varia de acordo com as características do tipo de resíduo empregado como substrato de fermentação e as condições de operação do biodigestor. Os principais constituintes do biogás são o metano $(60-80 \%$ v/v) e o dióxido de carbono (20-40\% v/v); outros gases, como sulfeto de hidrogênio, nitrogênio, hidrogênio e monóxido de carbono, também podem compor o biogás, porém em menores concentrações.

De acordo com Salomon \& Lora (2005), o poder calorífico do biogás é variável, sendo aproximadamente de 22500 a $25000 \mathrm{~kJ} \mathrm{~m}^{-3}$. Segundo Schalch \& Moraes (1988), um metro cúbico de biogás possui equivalência energética a $0,80 \mathrm{~kg}$ de carvão vegetal, $1,5 \mathrm{~kg}$ de lenha, $0,55 \mathrm{~L}$ de óleo diesel $0,45 \mathrm{~kg}$ de GLP e 1,43 kWh em energia elétrica.

O processo contínuo de produção de biogás já é bem conhecido, em especial a geração de gás metano a partir de esgotos sanitários e de dejetos de animais. Recentemente, pesquisadores se têm voltado para o uso de resíduos agrícolas como biomassa na geração do biogás.

Lastella et al. (2002), empregaram rejeitos hortifruti de supermercados como substrato e produziram, em média, 2067 $\mathrm{L}$ de biogás dia ${ }^{-1}$, com produtividade de $51,6 \mathrm{~L} \mathrm{~kg}^{-1} \mathrm{dia}^{-1}$. Bouallagui et al. (2003; 2004a; 2004b; 2005) utilizaram o mesmo tipo de biomassa e avaliaram o efeito do teor de sólidos totais, ST, no meio de fermentação e do tempo de retenção hidráulico, $\mathrm{TR}_{\mathrm{H}}$, sobre a produção de biogás. A maior velocidade de produção de biogás obtida pelos autores foi de 2,62 $\mathrm{L} \mathrm{L}^{-1} \mathrm{dia}^{-1}$ com rendimento em biogás de $594,96 \mathrm{~L} \mathrm{~kg}^{-1} \mathrm{ST}$ e concentração de $\mathrm{CH}_{4}$ de $55 \%$ v/v nas condições operacionais de $\mathrm{ST}=6 \% \mathrm{~m} / \mathrm{m}$ e $\mathrm{TR}_{\mathrm{H}}=12$ dias.
Gomes et al. (2006), utilizando como substrato lixos orgânicos compostos de frutas e vegetais obtiveram um rendimento em biogás de até $0,8 \mathrm{~L} \mathrm{~kg}^{-1}$ de sólidos voláteis.

Especificamente em relação aos rejeitos da bananicultura, tem-se os trabalhos de Deivanai \& Kasturi Bai (1995), Bardiya et al. (1996) e Kalia et al. (2000), em que o primeiro grupo realizou a biometanização da banana in natura (rejeito) e alcançou o rendimento máximo de $9,22 \mathrm{~L} \mathrm{~kg}^{-1} \mathrm{ST}$. Bardiya et al. (1996) empregaram cascas da banana como substrato e produziram de 65 a $127 \mathrm{~L} \mathrm{CH}_{4} \mathrm{~kg}^{-1}$ ST enquanto Kalia et al. (2000), utilizaram o pseudocaule da bananeira Musa indica quimicamente tratado para a redução do teor de fibras e produziram biogás com rendimento de $271 \mathrm{~L} \mathrm{~kg}^{-1} \mathrm{ST}$.

Devido à possibilidade da venda de créditos de carbono, a produção de biogás novamente ganha atenção e começa a ter destaque na cadeia produtiva. Conforme Salani (2007), o mercado de crédito de carbono surgiu a partir do Protocolo de Kyoto e gerou transações de 9,4 bilhões de euros, em 2005; ainda de acordo com o autor, o primeiro leilão de créditos de carbono realizado na América Latina foi concretizado em setembro de 2007, na Bolsa de Mercadorias e Futuros de São Paulo. O banco belgo-holandês Fortis comprou os 808,45 mil créditos ofertados a US\$16,20 cada um, com ágio de 27,6\% sobre o preço mínimo proposto.

Com este contexto, o trabalho foi desenvolvido com o objetivo de se avaliar a possibilidade do uso dos resíduos lignocelulósicos cascas de banana, engaço, pseudocaule e folhas de bananeiras como substrato de fermentação no processo de metanização.

\section{MATERIAL E MÉTODOS}

Biomassa: Os resíduos lignocelulósicos casca de banana, engaço, folhas e pseudocaule da bananeira Musa cavendischii, foram fornecidos por uma empresa agroindustrial da região nordeste de Santa Catarina. Esses resíduos foram cominuídos primeiramente em triturador industrial e em seguida em liquidificador doméstico de $2 \mathrm{~L}$. Todo o processo de cominuição foi realizado em meio aquoso até a obtenção de uma massa fluida de baixa viscosidade contendo sólidos de tamanho médio abaixo de $3 \mathrm{~mm}$ (inspeção visual).

Ensaios de fermentação: Foram realizados quatorze ensaios de biodegradação, em três etapas distintas, conduzidos a $30{ }^{\circ} \mathrm{C} \mathrm{e} \mathrm{pH} \mathrm{7,2.} \mathrm{Como} \mathrm{inóculo,} \mathrm{empregou-se} \mathrm{suspensão} \mathrm{mi-}$ crobiana obtida de biodigestor em operação em granja de criação de suinos.

Na primeira etapa determinou-se as concentrações ideais de cada um dos resíduos no meio de biodegradação. A concentração máxima de cada um dos resíduos avaliados nesses ensaios, expressa em grama de sólidos totais por litro (g ST $\left.\mathrm{L}^{-1}\right)$, foi função do volume de trabalho planejado $\left(\mathrm{V}_{\mathrm{T}}\right)$ e do volume máximo de biomassa possível de ser triturada sem, contudo, ultrapassar o $\mathrm{V}_{\mathrm{T}}$ após a sua cominuição. Esses valores foram de 27,0 $\mathrm{g} \mathrm{ST} \mathrm{L}^{-1}$ para as cascas de banana, 16,7 g ST L ${ }^{-1}$ para o engaço, $22,1 \mathrm{~g} \mathrm{ST} \mathrm{L}^{-1}$ para as folhas e $8,5 \mathrm{~g}$ ST L ${ }^{-1}$ para o pseudocaule. De acordo com a caracterização dos resíduos realizada por Conradi et al. (2006), referidos 
valores corresponderam às seguintes concentrações de massa úmida (mu) de substrato no meio de fermentação: 237,6 , 292,3, 137,0 e 182,0 g mu L-1, respectivamente. A partir dessas concentrações, identificadas por 1:1, adicionou-se água de diluição para as proporções de 1:2 e 1:4, totalizando três diferentes concentrações para cada um dos substratos avaliados: Ensaios E1 (1:4, 1:2, 1:1), Ensaios E2 (1:4, 1:2, 1:1), Ensaios E3 (1:4, 1:2, 1:1) e Ensaios E4 (1:4, 1:2, 1:1). Cada um desses ensaios foi realizado em triplicata e conduzido em frascos Erlenmeyer de $250 \mathrm{~mL}$ contendo $100 \mathrm{~mL}$ de $\mathrm{V}_{\mathrm{T}}$. Como incubadora foi empregado o agitador orbital Certomat-HR com frequência de agitação de $100 \mathrm{~min}^{-1}$.

Realizaram-se, na segunda etapa, dois ensaios de biodigestão da mistura de resíduos selecionada na etapa anterior com o objetivo de se avaliar os efeitos da hidrólise ácida da biomassa sobre a produção de biogás: Ensaio E5 - uso de biomassa in natura e Ensaios E6 - hidrólise prévia da biomassa. Conduziu-se os ensaios em garrafas plásticas de $1 \mathrm{~L}$ com $\mathrm{V}_{\mathrm{T}}=500 \mathrm{~mL}$ contendo, como substrato, aproximadamente $20 \mathrm{~g} \mathrm{ST} \mathrm{L}^{-1}$ composto dos resíduos casca de banana, folhas e pseudocaule da bananeira com as concentrações de 50,25 e $25 \% \mathrm{~m} \mathrm{~m}^{-1}$, respectivamente. Estabeleceu-se a composição desta mistura a partir dos resultados obtidos na etapa anterior. Para a hidrólise ácida dos resíduos se empregou $\mathrm{H}_{2} \mathrm{SO}_{4}$ na concentração de $1,0 \% \mathrm{~m} \mathrm{~m}^{-1}$, conforme indicado por Yadvika et al. (2004). O processo de hidrólise foi conduzido em autoclave a vapor a $120{ }^{\circ} \mathrm{C}$ durante $15 \mathrm{~min}$. $\mathrm{O}$ volume de inóculo empregado foi de $10 \%$ do volume de trabalho.

Avaliaram-se, na última etapa, os ensaios de metanização da biomassa em biorreator New Brunswick, modelo SF-116 com dorna de $10 \mathrm{~L}$ e com sistema automático de controle de $\mathrm{pH}$, temperatura e agitação (Ensaio 7). $\mathrm{O} \mathrm{V}_{\mathrm{T}}$ foi de $5 \mathrm{~L}$ e o volume de inóculo foi de $50 \%$ desse volume. A frequência de agitação foi de $130 \mathrm{~min}^{-1}$ utilizando-se, como agitador, duas turbinas, cada uma com seis pás planas (flat-blade) de diâmetro $75 \mathrm{~mm}$. A concentração inicial de substrato foi a mesma daquela empregada na segunda etapa. O tempo de retenção hidráulica foi de 35 dias.

Métodos analíticos: Retiraram-se, para as duas primeiras etapas dos ensaios, amostras no início de cada processo (após inoculação), com 15 dias de fermentação e no tempo final da fermentação; nessas etapas cada biodigestor (Erlenmeyer ou garrafa plástica) constitui uma amostra. Na etapa desenvolvida em biorreator New Brunswick as amostras foram retiradas a cada sete dias de processo. Realizaram-se as seguintes análises: (1) determinação das concentrações de ST através de análise gravimétrica empregando-se cadinhos de porcelana contendo, cada um, $5 \mathrm{~mL}$ de amostra úmida e tempo de secagem de $48 \mathrm{~h}$ a $105^{\circ} \mathrm{C}$; (2) determinação da DQO através de Kit DQO Reagente da Hach Company, na faixa de 0 a 1500 $\mathrm{mgO}_{2} \mathrm{~L}^{-1}$, código 21259, conforme metodologia fornecida pelo fabricante juntamente com o produto; (3) determinação do volume de biogás gerado no biorreator New Brunswick a partir da leitura da altura da coluna de água deslocada no interior de uma proveta de $2 \mathrm{~L}$ emborcada em uma bandeja também com água. Na parte superior da proveta foram feitos dois furos, aos quais se fixou um tubo de vidro para entrada do biogás além de um termômetro para leitura contínua da sua temperatura. No tubo de vidro foi adaptado um conector em Y com um septo de vedação para retiradas periódicas de amostras do biogás produzido. Neste sistema o biogás do biodigestor foi conduzido através de tubo de silicone $(5 \mathrm{~mm}$ de diâmetro interno) até a proveta e por meio da sua pressão manométrica exercida sobre a superfície de água, a coluna de líquido foi empurrada para fora da mesma, tornando possível a leitura direta do volume de biogás gerado. A partir do valor de temperatura do biogás contido na proveta e se considerando a mistura gasosa como gás ideal, foi convertido o volume de gás gerado por dia em volume de gás nas Condições Normais de Temperatura e Pressão (CNTP) e expresso na unidade $\mathrm{L}_{\mathrm{CNTP}}$ dia ${ }^{-1}$; (4) determinação da composição do biogás: a caracterização do biogás gerado foi realizada a partir das determinações das concentrações dos gases $\mathrm{CH}_{4}, \mathrm{CO}_{2} \mathrm{e}$ $\mathrm{H}_{2} \mathrm{~S}$ em cromatógrafo a gás Agilent, série 6890, com mostrador automático série 7683, empregando-se coluna HP-PLOT Q da Agilent (Port n. 19091P-Q04) com 30 m de comprimento, diâmetro 0,32 mm e filme de espessura $20 \mu \mathrm{m}$. Usou-se, como amostra, uma única coleta do biogás para cada tempo de fermentação avaliado. O biogás foi coletado em ampola de vidro de $300 \mathrm{~mL}$ com tampa roscada e vials numa extremidade e, na outra, uma torneira esmerilhada para entrada da amostra. Antes da coleta da amostra, a ampola de vidro foi lavada com ar atmosférico para se retirar possíveis impurezas, com o auxilio de uma bomba a vácuo; em seguida foi fechada a ampola com vácuo e coletado $300 \mathrm{~mL}$ de biogás no sistema de proveta acoplada ao biodigestor. A injeção da amostra no forno do cromatógrafo $(1 \mathrm{~mL})$ foi realizada manualmente através de seringa Hamilton Pat.eb. 315080 com êmbolo de teflon e capacidade volumétrica de 5,0 mL. Entre cada amostra injetada foi realizada a limpeza da seringa através de repetidas sucções de ar ambiente; no forno, a amostra foi, inicialmente, aquecida a $45^{\circ} \mathrm{C}$ e, em seguida, elevada para $90{ }^{\circ} \mathrm{C}$ (velocidade média de aquecimento de $\left.25^{\circ} \mathrm{C} \mathrm{min}-1\right), 240{ }^{\circ} \mathrm{C}(15$ ${ }^{\circ} \mathrm{C} \mathrm{min}-1$ ) e $260{ }^{\circ} \mathrm{C}\left(10^{\circ} \mathrm{C} \mathrm{min}^{-1}\right)$, permanecendo 2 minutos em cada uma dessas temperaturas até ser conduzida ao detector. Utilizou-se o detector de condutividade térmica (TCD) com temperatura de $250^{\circ} \mathrm{C}$ e vazão de referência He a $20 \mathrm{~mL} \mathrm{~min}^{-}$ ${ }^{1}$ e $_{2}$ (makeup) a 7,0 mL min ${ }^{-1}$. Como gás de arraste foi empregado o gás He com vazão constante de $2,2 \mathrm{~mL}$. min $^{-1} \mathrm{e}$, como padrão, uma mistura primária dos gases analisados contendo (em porcentagem volumétrica) 40,030\% de $\mathrm{CH}_{4}$, $29,950 \%$ de $\mathrm{CO}_{2}$ e $30,020 \%$ de $\mathrm{H}_{2} \mathrm{~S}$, fornecido pela empresa White Martin, Joinville-SC.

Os dados foram submetidos à análise de variância dos valores médios das amostras, através do Teste de Tukey com nível de significância de 5\% (ANOVA).

\section{RESULTADOS E DISCUSSÃO}

Na Tabela 1 se encontram os resultados obtidos nos ensaios E1 a E4 empregando-se, de forma isolada, cada um dos resíduos avaliados.

Conforme a Tabela 1, após 15 dias de processo, os ensaios E1-1:2 e E1-1:1 apresentaram respectiva redução média da DQO de 41,6 e 62,7\%, em relação aos seus valores iniciais. 
Tabela 1. Valores de ST e DQO obtidos na biodigestão dos resíduos cascas de bananas (E1), engaço (E2), folhas (E3) e pseudocaule de bananeiras (E4), empregando-se diferentes concentrações de substrato (1:1, 1:2 e 1:4)

\begin{tabular}{|c|c|c|c|c|c|c|}
\hline \multirow[t]{2}{*}{ Ensaio } & \multicolumn{3}{|c|}{ ST (g ST L-1) } & \multicolumn{3}{|c|}{ DQO $\left(g\right.$ DQO $\left.L^{-1}\right)$} \\
\hline & $0 a^{*}$ & $15 b^{*}$ & $30 c^{*}$ & $0 \mathrm{~d}^{*}$ & $15 \mathrm{e}^{*}$ & $30 \mathrm{f*}$ \\
\hline E1-1:4 & $8,8 \pm 1,0 \mathrm{~b}$ & $7,4 \pm 0,3 a$ & $5,2 \pm 0,0$ & $8,0 \pm 2,1 \mathrm{e}$ & $5,3 \pm 0,6 d$ & 0 \\
\hline$=1-1: 2$ & $14,0 \pm 0,0$ & $7,7 \pm 0,2$ & $7,2 \pm 0,2$ & $12,5 \pm 1,0$ & $7,3 \pm 0,6$ & 0 \\
\hline E1-1:1 & $27,0 \pm 0,2$ & $21,9 \pm 0,0$ & $12,7 \pm 0,1$ & $24,7 \pm 2,5$ & $9,2 \pm 3,5$ & 0 \\
\hline E2-1:4 & $4,9 \pm 0,7 b c$ & $=4,5 \pm 0,1 \mathrm{a}$ & $5,4 \pm 0,1 \mathrm{a}$ & $4,8 \pm 1,8$ ef & $3,4 \pm 1,6 \mathrm{df}$ & $f 3,0 \pm 0,9$ de \\
\hline E2-1:2 & $8,9 \pm 1,4$ & $6,7 \pm 0,0$ & $7,3 \pm 0,2$ & $* *$ & $2,6 \pm 0,9 f$ & $2,6 \pm 1,2 \mathrm{e}$ \\
\hline E2-1:1 & $16,7 \pm 2,3$ & $10,8 \pm 0,9$ & $9,5 \pm 0,5$ & $6,3 \pm 0,7$ & $4,4 \pm 0,8 \mathrm{f}$ & $3,7 \pm 0,8 \mathrm{e}$ \\
\hline E3-1:4 & $8,6 \pm 0,5$ & $5,1 \pm 0,2 c$ & $5,4 \pm 0,1 b$ & $5,3 \pm 0,9$ & $1,1 \pm 0,4$ & 0 \\
\hline E3-1:2 & $10,8 \pm 0,1$ & $8,4 \pm 0,2 c$ & $8,0 \pm 0,8 b$ & $8,0 \pm 1,0$ & $1,7 \pm 0,5$ & 0 \\
\hline E3-1:1 & $22,1 \pm 0,1$ & $17,5 \pm 0,2 c$. & $18,1 \pm 0,4 b$ & $9,7 \pm 0,9$ & $3,2 \pm 1,1$ & 0 \\
\hline E4-1:4 & $4,2 \pm 0,4$ & $2,8 \pm 0,1$ & $* *$ & $2,6 \pm 0,7$ & 0 & ** \\
\hline $4-1: 2$ & $5,2 \pm 0,1$ & $3,8 \pm 0$ & ** & $4,0 \pm 0,2$ & 0 & ** \\
\hline E4-1:1 & $8,5 \pm 0,5$ & $6,5 \pm 0,2$ & ** & $7,0 \pm 0,2$ & 0 & ** \\
\hline
\end{tabular}

*Letras iguais às letras de cada t $(0,15$ e 30 dias), específicas a ST ou DQO, demonstram médias sem diferença significativa pelo teste de Tukey, com nível de significância de 5\%; ** não determinado.

Neste período, não houve diferença significativa entre os valores da DQO para o ensaio E1-1:4, demonstrando assim uma diluição excessiva do substrato em relação aos ensaios 1:2 e 1:1. Nas condições experimentadas, a concentração de 27,0 $\mathrm{g} \mathrm{ST} \mathrm{L}^{-1}$ (E1-1:1) indicou maior potencial de degradação sendo considerada, portando, como boa indicativa da concentração ideal para a continuidade dos trabalhos. Desconsiderando-se a contribuição do inóculo nesse valor, a concentração de ST relativa somente ao substrato foi de 23,8 g ST $\mathrm{L}^{-1}$.

Com relação às folhas esses valores de porcentagem de redução da DQO relativos a cada concentração de substrato empregada, foram de 79,2\% (Ensaio E3-1:4), 78,7\% (Ensaio E31:2) e 67,0\% (Ensaio E3-1:1). Os respectivos valores iniciais de ST, devidos somente ao substrato (sem o inóculo), foram 3,3, 9,6 e 16,8 g ST L ${ }^{-1}$ sendo, portanto, a concentração em torno de $3 \mathrm{~g} \mathrm{ST} \mathrm{L}^{-1}$ a mais indicada para a biodegração desse material.

Verifica-se, na Tabela 1, que o pseudocaule (Ensaios E4) foi totalmente biodegradado nos primeiros 15 dias de processo enquanto que para as cascas (Ensaios E1) e para as folhas (Ensaios E3) foi necessário um maior tempo de fermentação. Este fato pode ser explicado devido às características físicas de cada um dos substratos pois o pseudocaule possui, além de menor ST, valor inferior de DQO.

Quando o engaço foi utilizado como substrato (Ensaios E2), os ensaios 1:4 e 1:2 não apresentaram diferenças significativas de DQO para os tempos de fermentação avaliados. Apenas o ensaio 1:1, apresentou em torno de $30 \%$ de redução da DQO nos primeiros 15 dias de processo; entretanto não se observou, estatisticamente, continuidade desta biodegradação. O seu valor de velocidade média de redução da DQO ( $\bar{\vartheta}$ VDQO) relativo aos primeiros 15 dias de processo foi de $0,13 \mathrm{~g} \mathrm{DQO} \mathrm{L}^{-1} \mathrm{dia}^{-1}$ para uma concentração inicial de $16,7 \mathrm{~g} \mathrm{ST} \mathrm{L}^{-1}$. Comparativamente ao emprego das cascas de banana como substrato, numa mesma proporção (1:1), com uma DQO de 1,03 g DQO L L dia $^{-1}$, o valor de DQO do engaço foi de aproximadamente oito vezes menor e, em relação às folhas da bananeira, (DQO $\left.=0,43 \mathrm{~g} \mathrm{DQO} \mathrm{L}^{-1} \mathrm{dia}^{-1}\right)$ e ao pseudocaule (DQO $\left.=0,47 \mathrm{~g} \mathrm{DQO} \mathrm{L}^{-1} \mathrm{dia}^{-1}\right)$ esta diferença foi da ordem de 3,5 vezes menor. Este baixo valor em DQO do engaço, sobretudo se comparado com o DQO do pseudocaule não era esperado. De acordo com estudos já realizados (Conradi et al., 2006), notou-se que o engaço possui propriedades físicas e químicas superiores às do pseudocaule para a biodigestão. Os autores concluíram, ainda, que entre os quatro tipos de resíduo apenas o pseudocaule, e não o engaço, merecia maior estudo para o seu emprego como substrato na biodigestão. Apesar desta discrepância, o engaço foi descartado para a continuidade dos estudos pois, em função da baixa quantidade do resíduo gerado no campo, comparativamente com os outros três substratos, não justificaria, neste momento, novos estudos para a elucidação das dúvidas aqui geradas.

Em função dos resultados observados nesses ensaios e se considerando que na instalação futura de um biodigestor industrial, deve-se procurar empregar, de forma conjunta, todos os resíduos biodegradáveis (visando a uma praticidade maior na operação do sistema) recomenda-se uma carga inicial do biodigestor composta de (em massa úmida) $50 \%$ de cascas, $25 \%$ de folhas e $25 \%$ de pseudocaule, com tempo de retenção de 15 a 30 dias.

Em relação à concentração ideal de sólidos totais no meio de fermentação, novos estudos precisam ainda ser realizados para a sua otimização, principalmente se for pretendido o uso de um sistema contínuo de biodigestão. Segundo Zennaki et al. (1996), nesse tipo de sistema a faixa ideal de operação é de 70 a $90 \mathrm{~g} \mathrm{ST} \mathrm{L}^{-1}$, ou seja, 4 vezes maior que a aqui planejado (cerca de $20 \mathrm{~g} \mathrm{ST} \mathrm{L}^{-1}$ ). Convém enfatizar que os autores empregaram dejetos de gado em seu trabalho e não resíduos vegetais; já Bouallagui et al. (2003), que empregaram refugos hortifruti de supermercado como substrato, recomendaram o emprego de $60 \mathrm{~g} \mathrm{ST} \mathrm{L}^{-1}$. Em ambos os casos, acima de $100 \mathrm{~g}$ ST $\mathrm{L}^{-1}$ a produção de biogás foi inibida.

Visando avaliar a contribuição da hidrólise ácida dos substratos sobre a produção de biogás, dois ensaios de metanização foram realizados com a mistura dos resíduos, já definida. No Ensaio E5 a mistura foi empregada in natura, sem pré-tratamento ácido e, no Ensaio E6, o substrato foi previamente submetido a hidrólise com $\mathrm{H}_{2} \mathrm{SO}_{4} 1 \%$. A Tabela 2 apresenta os resultados obtidos.

De acordo com a Tabela 2, é conveniente destacar que, em comparação com o substrato in natura (Ensaio E5) o uso da hidrólise prejudicou o processo de produção de biogás. O

Tabela 2. Valores médios de produção de biogás (\% v/v) com substrato in natura composto de $50 \%$ de casca de banana, $25 \%$ de folhas e $25 \%$ de pseudocaule de bananeiras (Ensaio E5) e com substrato previamente hidrolisado (Ensaio E6)

\begin{tabular}{ccccccc}
\hline \multirow{2}{*}{ Parâmetro } & \multicolumn{6}{c}{ Tempo de processo (dias) } \\
\cline { 2 - 7 } & $\mathbf{0}$ & $\mathbf{7}$ & $\mathbf{1 4}$ & $\mathbf{2 1}$ & $\mathbf{2 8}$ & $\mathbf{3 5}$ \\
$\mathrm{CH}_{4}(\mathrm{E} 5 / \mathrm{E} 6)$ & $0 / 0$ & $0,3 / 0$ & $6,0 / 0$ & $26,0 / 0$ & $25,4 / 0$ & $22,9 / 0$ \\
$\mathrm{CO}_{2}(\mathrm{E} 5 / \mathrm{E} 6)$ & $0 / 0$ & $99,5 / 100,0$ & $93,9 / 100,0$ & $74,0 / 95,7$ & $74,6 / 96,4$ & $77,1 / 97,1$ \\
$\mathrm{H}_{2} \mathrm{~S}(\mathrm{E} 5 / \mathrm{E} 6)$ & $0 / 0$ & $0 / 0$ & $0 / 0$ & $0,0 / 4,28$ & $0,0 / 3,6$ & $0,0 / 2,8$ \\
\hline
\end{tabular}


objetivo maior desse tipo de processo é obter alto rendimento em biogás e alta concentração de $\mathrm{CH}_{4}$ no biogás gerado; além de não ter sido detectada a formação de $\mathrm{CH}_{4}$ no biogás gerado, a hidrólise ácida conduziu à formação de $\mathrm{H}_{2} \mathrm{~S}$ (Ensaio E6).

A produção de $\mathrm{H}_{2} \mathrm{~S}$ a partir do substrato hidrolisado pode ser explicada pelo fato de que a hidrólise, ao ser realizada com ácido sulfúrico com posterior correção do $\mathrm{pH}$ do meio de fermentação com hidróxido de sódio, possibilitou a formação de sulfato de sódio. Segundo Janssen et al. (1999), alguns grupos de bactérias que usam o catabolismo oxidativo podem utilizar o sulfato de sódio como fonte inorgânica de energia e o reduzem a $\mathrm{H}_{2} \mathrm{~S}$. De acordo com Foresti (1994), a redução biológica de sulfato em digestores anaeróbios é, em geral, considerada como um processo indesejável, por duas razões: o sulfato oxida material orgânico que deixa de ser transformado em metano e no processo se forma o gás sulfídrico, que é corrosivo e confere odor muito desagradável tanto à fase líquida como ao biogás, além de poder ser tóxico para o processo de metanogênese.

A metanização da mistura dos resíduos in natura em biorreator de bancada, utilizando inóculo na concentração de $50 \%$ do $\mathrm{V}_{\mathrm{T}}$ e ST inicial de 29,5 $\mathrm{g} \mathrm{ST} \mathrm{L}^{-1}$, propiciou maior controle do processo e conduziu a uma velocidade maior de produção de biogás. A Tabela 3 apresenta os resultados obtidos neste ensaio (Ensaio E7).

Durante os 35 dias de processo a produção acumulada de biogás foi de aproximadamente $36 \mathrm{~L}_{\mathrm{CNTP}}$, resultando no rendimento médio de $244 \mathrm{~L}_{\mathrm{CNTP}} \mathrm{kg}^{-1} \mathrm{ST}$; entretanto, pode-se observar, na Tabela 3 , que a proporção de $\mathrm{CH}_{4}$ no biogás gerado no início do processo foi bem menor que a esperada $(50-80 \%)$. Somente após 21 dias de processo a produção de metano atingiu esta faixa de valores, conincidindo com o tempo em que o valor de DQO apresentou diferença significativa aos tempos anteriores (14, 7 e 0 dias). Este comportamento é típico de tal tipo de processo, uma vez que o inóculo procedente de biodigestor em operação com dejetos de suínos necessita de alguns dias para adaptação com o novo tipo de substrato.

Este valor foi maior que o observado por Deivanai \& Katuri Bai (1995) e por Kalia et al. (2000), que empregaram, como substrato de fermentação, pseudocaule; os autores alcançaram valores de rendimento da ordem de $9 \mathrm{~L} \mathrm{~kg}^{-1} \mathrm{ST}$ com 30 dias de metanização e de $229 \mathrm{~L} \mathrm{~kg}^{-1} \mathrm{ST}$ com 57 dias, respectivamente; no primeiro caso foi utilizado o substrato in natura e, no segundo, substrato com pré-tratamento químico para quebra das fibras existentes no material.

Utilizando resíduos sólidos vegetais advindos de central de abastecimento e feira livre, resultando em uma carga orgânica de $600 \mathrm{~kg}$ de substrato $\mathrm{m}^{-3}\left(120 \mathrm{~kg} \mathrm{ST} \mathrm{m}^{-3}\right)$, Leite et al. (2003) obtiveram, após 240 dias de fermentação, uma produção acumulada de 1200 L de biogás contendo, em média, $60 \%$ (percentagem em volume) de gás metano. Considerando o volume de trabalho do biorreator empregado pelos autores (2200 L), esta produção conduziu ao rendimento em biogás de $18,3 \mathrm{~L}_{\mathrm{CNTP}} \mathrm{kg}^{-1} \mathrm{ST}$. Esse rendimento é da ordem de $65,6 \%$ menor que o obtido neste trabalho $\left(244 \mathrm{~L}_{\mathrm{CNTP}} \mathrm{kg}^{-1} \mathrm{ST}\right)$. Essa diferença percentual pode ser explicada pelos diferentes tipos de inóculo empregados e pelos diferentes tipos de substratos utilizados. Enquanto Leite e colaboradores utilizaram lodo de estação de tratamento de esgotos sanitários como inóculo e mistura de diferentes tipos de frutas e vegetais como substrato, neste trabalho empregou-se como inóculo suspensões microbianas obtidas de biodigestores em operação e como substrato, resíduos vegetais da bananicultura.

O rendimento obtido neste trabalho denota a potencialidade do uso dos resíduos casca de bananas, folhas e pseudocaule como substrato de fermentação na geração de biogás. Tendo em vista tanto a capacidade calorífica do biogás (5000 kcal kg-1) em relação à lenha com $40 \%$ de umidade (2400 $\mathrm{kcal} \mathrm{kg}^{-1}$ ), como o custo médio de obtenção de ambos (R\$ $0,65 \mathrm{~kg}^{-1}$ e $\mathrm{R} \$ 0,35 \mathrm{~kg}^{-1}$, respectivamente), verifica-se que a produção de biogás a partir desses resíduos passa a ser viável economicamente a partir do uso de biodigestores com capacidade mínima de geração diária de $10 \mathrm{~m}^{3}$ de biogás. A construção de um biodigestor tipo indiano que necessita, basicamente, apenas de cimento, areia e tijolo, com capacidade volumétrica de $50 \mathrm{~m}^{3}$ de volume, tem custo aproximado de $\mathrm{R} \$ 8.000,00$. Tomando-se como base de cálculo um rendimento mínimo de biogás de $15 \mathrm{~L} \mathrm{~kg}^{-1} \mathrm{ST}$ pode-se gerar até 3650 $\mathrm{m}^{3}$ de biogás por ano; este valor, em termos econômicos, equivale a aproximadamente $\mathrm{R} \$ 4.500,00$, tornando o retorno do investimento original em torno de 3 anos do início de operação.

Nesta análise não se considerou o provável ganho financeiro advindo dos créditos de carbono que podem ser comercializados nas Bolsas de Valores desde que se possuam as certificações RCEs (Reduções Certificadas de Emissões emitidas pelo Conselho Executivo do MDL - Mecanismo de Desenvolvimento Limpo com aprovação da ONU - Organização das Nações Unidas) ou na sigla em inglês CERs.

Tabela 3. Valores médios \pm desvio padrão de $\mathrm{DQO}$ e valores médios de volume $\left(\mathrm{V}_{\mathrm{g}}\right)$ e composição $\left(\mathrm{CH}_{4}, \mathrm{CO}_{2}\right.$ e $\left.\mathrm{H}_{2} \mathrm{~S}\right)$ do biogás gerado em função do tempo de biodigestão dos resíduos in natura em biorreator de bancada (Ensaio E7)

\begin{tabular}{ccccccc}
\hline \multirow{2}{*}{ Parâmetro } & \multicolumn{5}{c}{ Tempo de processo (dias) } \\
\cline { 2 - 7 } DQO (g DQO L-1) & $\mathbf{0} \mathrm{a}^{*}$ & $\mathbf{7} \mathbf{b}^{*}$ & $\mathbf{1 4} \mathbf{c}^{*}$ & $\mathbf{2 1} \mathbf{d}^{*}$ & $\mathbf{2 8} \mathrm{e}^{*}$ & $\mathbf{3 5} \mathbf{f}^{*}$ \\
$\mathrm{Vg}(\mathrm{LCNTP} \mathrm{dia-1)}$ & $25,2 \pm 2,7 \mathrm{~b}$ & $20,5 \pm 1,6 \mathrm{ac}$ & $17,7 \pm 2,6 \mathrm{~b}$ & $11,6 \pm 1,7 \mathrm{e}$ & $9,8 \pm 0,7 \mathrm{~d}$ & $3,8 \pm 1,1$ \\
$\mathrm{CH} 4(\% \mathrm{v} / \mathrm{v})$ & 0 & 0,62 & 1,10 & 1,25 & 1,60 & 1,05 \\
$\mathrm{CO} 2(\% \mathrm{v} / \mathrm{v})$ & 0 & 38,38 & 32,09 & 59,37 & 65,52 & 66,83 \\
$\mathrm{H} 2 \mathrm{~S}(\% \mathrm{v} / \mathrm{v})$ & 0 & 60,54 & 67,90 & 40,62 & 34,47 & 33,16 \\
\hline
\end{tabular}

*Letras iguais às letras de cada $\mathrm{t}(0,7,14,21,28$ e 35 dias), específicas a ST ou DQO, demonstram médias sem diferença significativa pelo teste de Tukey, com nível de significância de $5 \%$ 


\section{CONCLUSÕES}

1. O engaço in natura não possui potencial para uso como substrato de fermentação na geração de biogás; os demais resíduos (casca de banana, folhas e pseudocaule) foram empregados com sucesso na produção de biogás alcançando o rendimento médio de $244 \mathrm{~L}_{\mathrm{CNTP}} \mathrm{kg}^{-1} \mathrm{ST}$ quando utilizados de forma conjunta.

2. A composição ideal do substrato para a metanização empregando-se conjuntamente os resíduos da bananicultura, foi definida como (em massa úmida): $50 \% \mathrm{~m} / \mathrm{m}$ de casca, $25 \%$ $\mathrm{m} / \mathrm{m}$ de pseudocaule e $25 \% \mathrm{~m} / \mathrm{m}$ de folhas.

3. O tratamento prévio do substrato através da hidrólise ácida com $\mathrm{H}_{2} \mathrm{SO}_{4}$ conduziu à formação de $\mathrm{H}_{2} \mathrm{~S}$ no biogás, gás malcheiroso e altamente corrosivo e inibiu a produção de $\mathrm{CH}_{4}$.

4. O processo mostrou ter viabilidade tanto técnica como econômica. O retorno do investimento na construção e operação de um biodigestor tipo indiano com capacidade mínima de geração diária de $10 \mathrm{~m}^{3}$ de biogás, é de 3 anos.

\section{LITERATURA CITADA}

Bardiya, N.; Somayaji, D.; Khanna, S. Biomethanation of banana pell and pineapple waste. Bioresource Technology, v.58, p.73-76, 1996.

Bouallagui, H.; Cheikh, R. B.; Marouani, L.; Hamdi, M. Mesophilic biogas production from fruit and vegetable waste in a tubular digester. Bioresource Technology, v.86, p.85-89, 2003.

Bouallagui, H.; Haouari, O.; Touhami, Y.; Cheikh, R. B. ; Marouani, L. ; Hamdi, M. Effect of temperature on the performance of an anaerobic tubular reactor treating fruit and vegetable waste. Process Biochemistry, v.39, p.2143-2148, 2004a.

Bouallagui, H.; Torrijos, M.; Godon, J. J.; Moletta, R.; Ben Cheikh, R.; Touhami, Y.; Delgenes, J. P.; Hamdi, M. Two-phases anaerobic digestion of fruit and vegetable wastes: Bioreactors performance. Biochemical Engineering Journal, v.21, p.193-197, 2004b.

Bouallagui, H.; Touhami, Y.; Bem Cheikh, R.; Hamdi, M. Bioreactor perfomance in anaerobic digestion of fruit and vegetable wastes. Process Biochemistry, v.40, p.989-995, 2005.

CEPA - Centro de Socieconomia e Planejamento Agrícola, Epagri, Governo do Estado de Santa Catarina. Síntese Anual da Agricultura de Santa Catarina, 2005-2006. htpp// www.cepa.epagri.sc.gov.br/Publicacoes/sintese_2006/ banana_2006.pdf, 7 Jun. 2007.
Conradi, V.; Reeck, S. C.; Souza, O.; Wisbeck, E. Determinação das propriedades físicas e químicas dos resíduos gerados na industrialização da banana visando a produção de biogás. Caderno de Iniciação à Pesquisa/UNIVILLE, v.8, p.760-764, 2006.

Deivanai. K.; Kasturi Bai, R. Batch biomethanation of banana trash and coir pith. Bioresource Technology. v.52, p.93-94, 1995.

EMBRAPA - Empresa Brasileira de Pesquisa Agropecuária. Embrapa fruta. http://www.jornalentreposto.com.br/anteriores/janeiro_2006/transporte.htm>17k, 28 Jun. 2008.

Foresti, E. Fundamento do processo de digestão anaeróbia. In. Seminario Latinoamericano: Tratamento Anaerobio de Águas Residuales 3, Montevideo, Anais... p. 97-110, 1994.

Gomes, X.; Cuetos, M. J.; Cara, J.; Morán, A.; García, A. I. Anaerobic co-digestion of primary sludege and the fruit and vegetable fraction of the municipal solid wastes: Conditions for mixing and evaluation of the organic loading rate. Renewable Energy, v.31, p.2017-2024, 2006.

Janssen, A.; Marcelis, C.; Buisman, C. Industrial applications of new sulphur biotechnology. Waste, v.21, p.55-57, 1999.

Kalia, V. C.; Sonakya, V.; Raizada, N. Anaerobic digestion of banana stem waste. Bioresource Technology, v.72, p.191-193, 2000.

Lastella, G.; Testa, C.; Cornacchia, G.; Notornicola, M.; Voltasio, F.; Sharma, V. K. Anaerobic digestion of semi-solid organic waste: biogas production and its purification. Energy Conversion and Management, v.43, p.63-75, 2002.

Leite, V. D.; Sousa, J. T.; Prasad, S.; Lopes, W. S.; Athayde Júnior, G. B.; Dantas, A. M. M. Tratamento de resíduos sólidos de centrais de abastecimento e feiras livres em reator anaeróbio de batelada. Revista Brasileira de Engenharia Agrícola e Ambiental, v.7, n.2, p.318-322, 2003.

Salomon, K. R.; Lora, E. E. S. Estimativa do potencial de geração de energia elétrica para diferentes fontes de biogás no Brasil. Biomassa \& Energia, v.2, n.1, p.57-67, 2005.

Salani, F. São Paulo ganha R \$ 34 milhões com crédito de carbono. Jornal Folha de São Paulo. http://www1.folha.uol.com.br/ folha/dinheiro/ult91u331829.shtml, 20 Set. 2007.

Schalch, V.; Moraes, A. J. Biogás: A energia vinda do lixo urbano e sua relação com a produção e característica do chorume. Revista de Limpeza Pública, p.21-30, 1988.

Yadvika, S.; Sreeckrishnan, T. R.; Kohli, S.; Rana, V. Enhancement of biogas production from solid substrates using different techniques -a review. Bioresource Technology, v.95, p.110, 2004.

Zennaki, B. Z.; Zadi, A.; Lamini, H.; Aubinear, M.; Boulif, M. Methane fermentation of cattle manure: effects of HRT, temperature and substrate concentration. Tropicultural v.14, 4, p.134-140, 1996. 